\section{Kidney \\ Blood Pressure Research}

Kidney Blood Press Res 2013;37:1-8

\title{
Variation in Presentation and Presence of DNA Adducts and p53 Mutations in Patients with Endemic Nephropathy - an Environmental Form of the Aristolochic Acid Nephropathy
}

\author{
Sandra Karanovića,f Ivana Vuković Lela ${ }^{a, f}$ Bojan Jelakovića \\ Kathleen G. Dickman ${ }^{b}$ Anamarija Kovač Peićc Damir Dittrichc Matej Kneževićc \\ Vesna Matijevićd Andrea S. Fernandes ${ }^{\mathrm{b}}$ Frederick Miller \\ aSchool of Medicine, University of Zagreb, Department of Nephrology, Hypertension, Dialysis and \\ Transplantation, University Hospital Center Zagreb, Zagreb, Croatia, bepartments of Pharmacological \\ Sciences \& Medicine/Nephrology State University of New York at Stony Brook, USA, 'General Hospital \\ "Dr. Josip Benčević" Slavonski Brod, Croatia, 'Outpatient Clinic for General Medicine, Slavonski Kobaš, \\ Croatia, eDepartments of Pathology State University of New York at Stony Brook, USA, fSK and IVL \\ contributed equally to the paper
}

\section{Key Words}

Aristolochic acid • Endemic nephropathy • Urothelial cell cancer

\begin{abstract}
Background: Endemic nephropathy (EN) and associated urothelial cell cancers (UUC) are an environmental form of aristolochic acid nephropathy where the most probable rout of ingestion of aristolochic acid (AA) was made by bread contaminated with $A A$, leading to chronic dietary intoxication. Clinical courses of three members of the same family, similarly exposed to toxin, who exhibited different clinical courses of the disease are presented. Methods: Questionnaires on AA exposure were taken. Tissue samples were obtained during therapeutic nephrouretectomies. Histopathology, immunohistochemical detection of p53, p53 mutation screening in tumor DNA and analysis on the presence of aristolactam (AL)-DNA adducts were performed. Results: Case 1 had UUC with typical EN histopathological signs, whereas Case 2 had bilateral UUCs with typical EN histopathological signs. In contrast, the patient in Case 3 initially showed renal insufficiency, complicated afterwards by right UUC, and later on by left UUC with histopathological end-stage chronic changes but without typical EN changes. AA-DNA adducts and specific p53 mutational spectra (A:T $\rightarrow T: A$ transversion) were
\end{abstract}




\section{Kidney Blood Pressure Research}

Kidney Blood Press Res 2013;37:1-8

\begin{tabular}{l|l}
\hline DOI: 10.1159/000343394 & (C) 2013 S. Karger AG, Base
\end{tabular}

Published onine: Fedruary 26, 2013

www.karger.com/kbr

Karanović et al.: Chronic Dietary Intoxication as a Cause of Aristolochic Acid Nephropathy - a Case Report

found in tissues of cases 1 and 2. Conclusion: Diverse clinical courses seem to be related not to differences in exposure but to differences in metabolic activation or detoxification of AA and/or DNA repair resulting from different genetic polymorphisms.

Copyright $\odot 2013$ S. Karger AG, Basel

\section{Introduction}

Aristolochic acid nephropathy (AAN) was first named as Chinese herb nephropathy. This syndrome was originally described in approximately 100 Belgian patients who unintentionally ingested aristolochic acid (AA) during their treatment at a weight-loss clinic [1-3]. Of these patients, only 5\% developed rapidly progressing end-stage renal disease [4]. Renal impairment was characterized by proximal tubular proteinuria, tubular atrophy, and hypocellular interstitial fibrosis that decreased in intensity from the outer to the inner cortex. In 40-46\% of the patients, nephropathy was followed by the development of upper urinary tract urothelial cancer (UUC). Exposure to AA was confirmed by detection of AADNA adducts $[5,6]$. The renal proximal tubule is the target for the nephrotoxic effects of AA. Toxicity has been linked to disruption of various cellular functions such as intracellular calcium homeostasis, mitochondrial permeability transition, and phospholipase A2 activity, among others [7].

More than 170 cases of patients with AAN have been reported worldwide, encompassing patients who were treated with herbal remedies containing AA [8]. Some patients, mainly from Asia, presented with a Fanconi-like syndrome. Proximal tubular proteinuria is a feature common to all patients with AAN. Recently, we reported that endemic (Balkan) nephropathy (EN), a disease affecting residents of rural villages located near tributaries of the Danube River, is related to AA exposure [9-12]. EN is also a chronic tubulointerstitial nephropathy that is frequently associated with UUC $[13,14]$ and renal histopathological features strikingly similar to those observed in AAN [15]. In contrast to cases of AAN where AA was ingested either inadvertently or intentionally as a part of a medicinal regimen, the most probable route of exposure in EN is chronic dietary intoxication from bread made with flour contaminated with Aristolochia $[9,10,12]$.

The aim of this study was to elucidate the clinical and pathological spectrum of EN in 3 members of the same family who were presumably exposed to AA under similar conditions but exhibited different clinical courses.

\section{Case Reports}

\section{Clinical course of patients from a family with EN}

Case 1. In 1993, a 53-year-old farmer from the Croatian endemic village of Slavonski Kobaš presented to his general practitioner with hematuria. His past medical history was non-contributory. He had no history of sustained or intermittent use of non-steroidal anti-inflammatory drugs, he denied the use of herbal teas, never smoked, and drank only occasionally. The subject had lived his entire life in this village, where he worked as a wheat farmer. His family history was remarkable, in that both of his parents and 1 aunt died of end-stage renal disease at a young age ( $<55$ years). At the time of presentation, the results of the patient's physical examination, including his blood pressure, were normal. Laboratory values for red blood cell count and hemoglobin concentration were also normal, whereas the serum creatinine level was mildly elevated $(192 \mu \mathrm{mol} / \mathrm{l})$. Urinalysis showed the presence of malignant epithelial cells with otherwise normal findings. Ultrasonography showed small kidneys. A tumor mass was found in the left kidney along with a slightly dilated renal pelvis. The patient was admitted to the Department of Urology, General Hospital Slavonski Brod, Croatia, where he underwent left-sided nephroureterectomy. Based on the findings of histopathological examination, he was diagnosed with urothelial cell cancer of the renal 


\section{Kidney Blood Pressure Research}

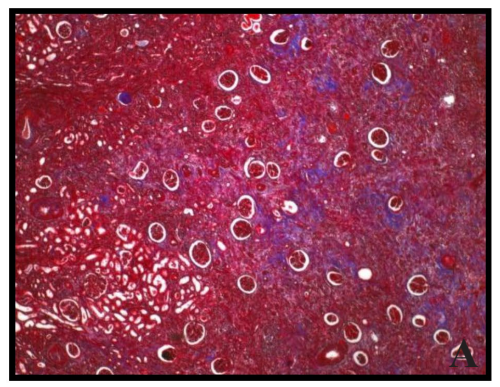

Kidney Blood Press Res 2013;37:1-8

Fig. 1. Histopathology of renal cortex (trichrome stain) for Case 1 (A), Case 2 (B) and Case 3 (C). Figures $\mathrm{A}$ and $\mathrm{B}$ depict good preservation of glomeruli, the absence of inflammation, and a gradient of tubular atrophy and interstitial fibrosis that decreases in severity from outer-to-inner cortex. In contrast, the notable histopathologic features in Figure $\mathrm{C}$ include the presence of numerous cysts and marked glomerular sclerosis. Original magnification 40x.

pelvis (T1, N0, M0; G3) and tubulointerstitial nephropathy that was histologically consistent with EN (Figure 1A). The patient was regularly monitored after the surgery, and while the results of urine cytological examinations were normal, serum creatinine level further increased. Eventually, in 2000, at the age of 60, hemodialysis was started, and UUC relapse was not observed.

Case 2. In 1994, a 49-year-old high school teacher from the city of Slavonski Brod, who was born in the endemic village of Slavonski Kobaš, where he shared the same familiar environment with his cousin (the patient in Case 1) until the age of 19, was referred to his general practitioner because of pain in the right lumbar region. He had no fever, rash, dysuria, or macrohematuria. However, 2 years before this episode, he had occasionally noticed blood in his urine, but did not consider this an important sign. Other than cholecystectomy in 1981, his past medical history was non-contributory. As with the patient in Case 1, he did not use anti-inflammatory drugs, other analgesic medications or herbal teas. He smoked more than 40 cigarettes per day over the last 20 years. Several of his family members, including an aunt and uncle (parents of Case 1), had been diagnosed with EN, and both of his parents had died of end-stage renal disease at a young age ( $<55$ years). His brother is currently on hemodialysis (the patient in Case 3). Clinically, he had no edema and his blood pressure was normal. Laboratory values for complete blood cell count and serum creatinine were normal, as was his urine sediment. Ultrasonography revealed dilatation of the right ureter, and intravenous urography confirmed the diagnosis of a right urothelial tumor. The patient was admitted to the Department of Urology, General Hospital Slavonski Brod, where he underwent right-sided ureterectomy with termino-terminal anastomosis. A diagnosis of transitional cell carcinoma of the ureter was established (T1, N0, M0; G2). Laboratory values at this time, including serum creatinine $(91 \mu \mathrm{mol} / \mathrm{l})$, were normal. In 1998, a tumor in the left kidney was identified by ultrasonography and confirmed by retrograde pyelography; malignant cells were found in the urine. At this time, serum creatinine level was elevated (141-207 $\mu \mathrm{mol} / \mathrm{l})$. Left-sided nephroureterectomy was performed, and transitional cell cancer of the renal pelvis was diagnosed (T3N0XM0; G3). Histopathological review of the renal parenchyma was consistent with a diagnosis of EN (Figure 1B). After the surgery, chemotherapy was initiated according to MVAC protocol (5 cycles of methotrexate, $50 \mathrm{mg}$ / $\mathrm{m}^{2}$; vinblastine, $5 \mathrm{mg} / \mathrm{m}^{2}$; adriamycin, $70 \mathrm{mg} / \mathrm{m}^{2}$; and cisplatin, $60 \mathrm{mg} / \mathrm{m}^{2}$ on days $1,2,15$, and 22). Subsequent examinations revealed no relapses of malignant disease, but renal function continued to decline. In 2009, at the age of 64, hemodialysis was initiated.

Case 3. In 1993, a 47-year-old metal worker from the city of Slavonski Brod, cousin of the patient in Case 1 and brother of the patient in Case 2, was admitted to the Department of Nephrology, General Hospital Slavonski Brod, for the evaluation of renal failure; his serum creatinine level was $251 \mu \mathrm{mol} / \mathrm{l}$. He was born in the endemic village of Slavonski Kobaš where he shared the same familiar environment with the patients in Case 1 and Case 2 until he was 


\section{Kidney \\ Blood Pressure Research}

Kidney Blood Press Res 2013;37:1-8

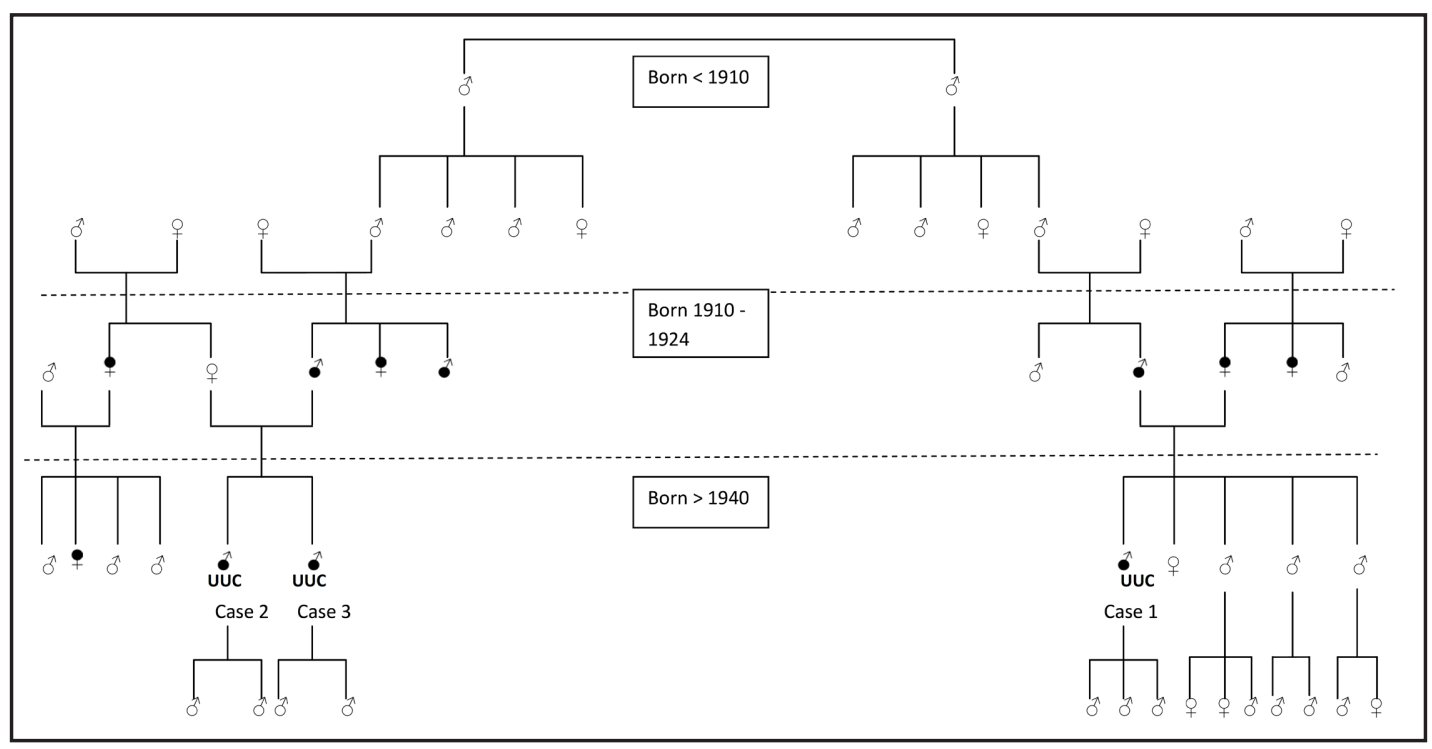

Fig. 2. Family tree of reported cases. Dark symbols are members with endemic nephropathy (EN); white symbols are members not affected with EN; UUC = upper urothelial cancer. Three cases from this report are marked.

18 years old. On admission, he appeared pale, he had no edema, and his blood pressure was $140 / 80 \mathrm{mmHg}$. His past medical history included tonsillectomy at age of 25 . He had not taken any medication, including anti-inflammatory drugs or other analgesics, and did not drink herbal teas. He started smoking when he was in a grammar school, and quit smoking at the age of 32. His family history was the same as that of the patient in Case 2. Renal ultrasonography showed hyperechogenic kidneys with reduced cortical thickness. His renal function continued to deteriorate; 7 years later, at the age of 54, continuous peritoneal dialysis was started. At the age of 58, he underwent surgery owing to colon cancer (Dukes B, T2N0M0) and was transferred to hemodialysis. In May 2008, transitional cell cancer of the bladder (T1N0M0, G3p) was diagnosed after transurethral bladder resection. Later during that year, he showed recurrence of bladder cancer; thus, BCG instillation was applied and no further treatment was recommended. Cystectomy and prophylactic bilateral nephroureterectomy were suggested, but the patient refused to undergo these procedures. In January 2009, at the age of 63, a right-sided nephroureterectomy was performed owing to transitional cell cancer of the renal pelvis (T3N0, M0; G3p) and ureter (pTis). Histopathological review of the renal parenchyma was not consistent with EN (Figure 1C). In October 2009, a left-sided nephroureterectomy was performed owing to hydronephrosis and ureter cancer (T1N0M0; G3p).

\section{Discussion}

Here, we presented the cases of 2 brothers and their first cousin affected by EN, who shared the same familiar environment for 18 years, in a Croatian endemic village. Several generations of their family were also affected by EN (Figure 2). Although only 1 of them (the patient in Case 1) had spent his whole life as a farmer in the endemic area, the other 2 had lived in the endemic village for a period which is assumed to be sufficiently long for exposure to the environmental nephrotoxin that causes EN. Recently, it was documented that AA from Aristolochia clematitis plants growing in wheat fields is the causative agent of EN and the associated UUC $[9,10,12]$. This finding is supported by the presence of AA-DNA adducts in renal tissues of patients from endemic areas and by the fingerprint mutational spectrum of p53 (A-T transversion) in 78\% of EN patients with UUC $[10,12]$. Based on this evidence, 


\section{Kidney Blood Pressure Research}

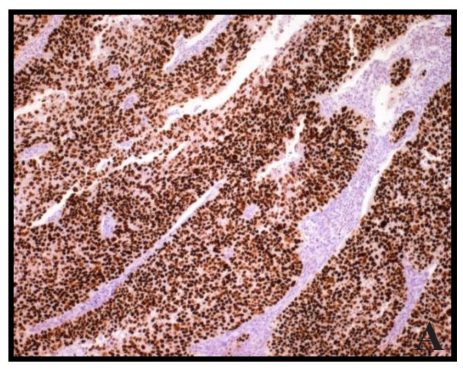

Kidney Blood Press Res 2013;37:1-8

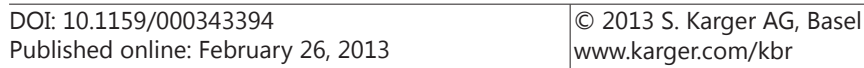

Fig. 3. p53 immunostaining in upper urinary tract urothelial cell tumors. Mutations in this tumor suppressor gene were detected in all three cases (see text). Positive p53 immunostaining (dark brown), evident in all three cases, involved over $90 \%$ of the tumor cells and was largely confined to the nucleus. p53 expression was absent in cells of the stroma and vasculature. Case 1 (A), Case 2 (B) and Case 3 (C). Hematoxylin was used as the counterstain. Original magnification 40x.

EN and AAN were concluded to be similar syndromes [16, 17]. However, contrary to all other cases described worldwide, where AAN was induced iatrogenically or inadvertently through consumption of herbal medicines, EN is an environmental disease where the toxic substance is most probably ingested in low doses over decades through bread. Herbal teas and other traditional herbal medications have been excluded as a source of ingested AA. Indeed, farmers from endemic villages were found to consume less tea, compared to farmers from non-endemic villages [18]. Moreover, in our cross-sectional study, we found that EN patients had observed $A$. clematitis growing in their wheat fields and meadows, as well as seeds of $A$. clematitis mixed with harvested wheat seeds, more frequently than had patients with other end-stage renal diseases [9]. Using an extended questionnaire, we found that all 3 patients in the cases reported herein recognized A. clematitis as a plant that grew in their wheat fields. They had further observed interspersing of Aristolochia and wheat seeds that caused contamination of their flour and bread with AA. All of the 3 patients also reported that 20 years ago, bread was baked in their household by using flour produced from their own wheat fields. These epidemiological data confirm that all the 3 subjects were similarly exposed to the environmental toxin for more than 15 years.

All the 3 subjects underwent nephroureterectomy. In Case 1 and Case 2, the histopathology clearly confirmed the diagnosis of EN (Figure 1A and 1B), whereas in Case 3 , the diagnosis was not conclusive for EN owing to the presence of extensive glomerular obliteration (Figure 1C). The patient in Case 3 might have had other chronic kidney diseases, possibly in combination with EN.

Formalin-fixed, paraffin-embedded tumor sections were used for immunohistochemical detection of p53 (P8999,1.50 Sigma Chemical Co., St. Louis, MO, US). Tumor DNA was screened for p53 mutations with Affymetrix p53 GeneChip oligonucleotide probe arrays (Santa Clara, CA, US) using a standard protocol as previously reported [11]. Immunohistochemistry showed that all the 3 patients had UUC that stained positive for p53 (Figure 3) and had p53 mutations in DNA isolated from tumors. Nevertheless, only the patients in Case 1 and Case 2 had fingerprint $\mathrm{A}>\mathrm{T}$ mutations (Case 1: $\mathrm{A}>\mathrm{T}$ at codon 251-1; Case 2: $\mathrm{A}>\mathrm{T}$ at codon 179-2 and $\mathrm{C}$ $>\mathrm{T}$ at codon 282-1) as reported previously for cases \#2 and \#8 in reference 9 . The patient in Case 3 had an $A>G$ transversion at codon 163-2, which is not typical of the mutagenic profile of AA. Although this might be attributed to the fact that not all p53 mutations are detected by this assay, because not all codons are screened, the histopathological findings allowed us to conclude that, most probably, the patient in Case 3 did not have EN, and that the urothelial cancer was not caused by AA. Because he was exposed in the same manner as the other 2 patients, who shared with him the same familiar environment, the observed differences in clinical courses could be explained by the presence of different polymorphisms in genes involved in the metabolism of AA and/or DNA repair. This is in agreement with previous observations of a few persons from an affected endemic household. 


\section{Kidney Blood Pressure Research}

Kidney Blood Press Res 2013;37:1-8

DOI: 10.1159/000343394

Published online: February 26, 2013

(C) 2013 S. Karger AG, Base

www.karger.com/kbr

DNA was isolated and assayed for the presence of aristolactam (AL)-DNA adducts by using the ${ }^{32} \mathrm{P}-$ postlabelling method previously described [10]. The DNA sources were exfoliated urothelial cells (Case 2), paraffin-embedded renal cortex (Case 1), or frozen renal cortex (Case 3). Adducts (AL.dA) were detected only in Case 1 ( 0.22 adducts $/ 10^{8}$ nucleotides using $4.2 \mu \mathrm{g}$ of DNA). Negative results were obtained with $14.3 \mu \mathrm{g}$ (Case 2) and $20 \mu \mathrm{g}$ (Case 3) of DNA, which is in agreement with the presumption that the patient in Case 3 was not an EN patient. The failure to detect adducts in Case 2 may be attributed to the DNA source, i.e., exfoliated tumor cells which are not expected to retain high adduct levels because of rapid cell proliferation. AL-DNA adducts were found in Belgium patients 89 months after withdrawal of treatment with herbal medicine containing AA [5]. It can be presumed that exposure to AA in endemic villages decreased 15 to 20 years ago owing to changes in harvesting and milling practices [19]. The presence of AL-DNA adducts in Case 1 after such a long period of time (more than 130-240 months) indicates that, as previously described in animal models, AL-DNA adducts are suitable lifelong present biomarkers of exposure to AA in humans [9, 19]. Deoxyadenosine adducts of $A A$ and $A>T$ mutations of p53 both were observed in Case 1. This is the first report on the simultaneous occurrence of these 2 crucial factors in a patient affected by EN. Such a finding was previously reported for an iatrogenic case of AAN [20].

The majority of subjects exposed to AA will not develop either urothelial cancer or tubulointerstitial disease. For example, only $5 \%$ of Belgian women who were inadvertently exposed to herbal therapies containing AA developed AAN. This is in close agreement with the prevalence of EN in endemic villages $[1,21,22]$. Depending on genetic polymorphisms, exposed subjects may develop either nephropathy, cancer, or both. This difference in clinical presentation is evident in our cases. The patient in Case 1 already showed advanced renal impairment when UUC was first diagnosed. In contrast, renal function remained normal in the patient in Case 2 until 4 years after the diagnosis of UUC, and only began to deteriorate when a tumor was established in the contralateral kidney. Nortier et al. [23] also reported the case of a patient with invasive UUC who did not show advanced renal failure. Interestingly, as in the patient in Case 2, this patient developed UUC in the contralateral kidney several years after cancer was first diagnosed. To the best of our knowledge, Case 2 is the first EN case of invasive UUC in which the patient presented with a completely normal renal function. The finding that EN could present exclusively (or initially) as UUC without evident nephropathy, caused us to modify the classification of EN and include this as a separate diagnostic criterion (Jelaković B, unpublished data).

Although EN does not have pathognomonic features, the cortical histopathological pattern, in the absence of other renal diseases, is highly suggestive of this clinical entity. In some patients (especially the elderly), hypertension, diabetes, obesity, or other renal diseases (perhaps as in Case 3) may overlap with EN, making a definitive histopathological diagnosis even more difficult. Hok-King Lo et al. [24] reported cases of patients with focal segmental glomerulonephritis complicated by AA nephropathy. Close collaboration between pathologists, nephrologists, and epidemiologists is mandatory for a proper diagnosis in such cases.

The family tree of the patients in our cases is presented in Figure 2. No EN patients were recognized in generations born before 1910 . While this could be related to a rather poorer diagnosis of kidney disease at the beginning of the last century, or to mortality at a younger age that masked the late onset of disease, it could also reflect less exposure to AA. Namely, at that time, farmers did not grow wheat as often as they did after World Wars I and II. Bread was mostly made from corn with which no mixing with $A$. clematits seeds would occur [19, unpublished data]. In the next generation, EN was diagnosed in 7 of 11 subjects, but none of them had UUC. Although tumors could have been present, they were probably asymptomatic; moreover, at that time, dialysis was not available, and the subjects probably died of uremia before they developed cancer. This is supported by the fact that members of this generation died on average at the age of 53 (range, 37-70); on the other hand, the average age at which the patients died of UUC in Croatian endemic villages was 70.2 (range, 51-82) in 2000-2005 [25]. A decline in the prevalence of EN is evident in the subsequent generation, where 4 


\section{Kidney \\ Blood Pressure Research}

Kidney Blood Press Res 2013;37:1-8

\begin{tabular}{l|l}
\hline DOI: 10.1159/000343394 & (C) 2013 S. Karger AG, Basel
\end{tabular}

Publisned oninne: February 26, 2013

www.karger.com/kbr

Karanović et al.: Chronic Dietary Intoxication as a Cause of Aristolochic Acid Nephropathy - a Case Report

of 11 family members developed EN, and UUC was diagnosed in 3 subjects. In 2 of them (Case 1 and Case 2) UUC was proven to be related to AA. Improved treatment of chronic kidney disease, and especially the introduction of dialysis, extended the lifespan during this time, prolonging the latent period of patients exposed to AA in endemic villages. However, it is also possible that the ingested AA dose was higher in these patients. Muniz-Martinez et al. [26] reported that the risk of developing end-stage renal disease linearly increased with AA dose, and that the cumulative dose of AA was higher in patients with UUC than in patients with AAN without this type of malignancy. Neither EN nor UUC were observed in 14 children of the last generation. This decline in prevalence is possibly related to changes in harvesting and milling practices and to the fact that most farmers currently do not bake their own bread. Instead, they now purchase bread made with common flour from local bakeries $[19$, unpublished data].

\section{Conclusion}

EN is an environmental form of the worldwide prevalent disease AAN. Case 1 and Case 2 are the first documented cases of this type of AAN in which the patients presented with different clinical courses. Diverse clinical courses seem to be related not to differences in exposure but to differences in metabolic activation or detoxification of AA and/or DNA repair resulting from different genetic polymorphisms (analyses are underway to further clarify this issue). The decreased number of patients with EN found in the last 2 generations of this family tree may reflect considerably reduced exposure to the environmental toxin after changes in farming and milling practices.

\section{Conflict of Interests}

Authors have no financial interest related to the material in the manuscript.

\section{Acknowledgements}

The authors thank Tratinčica and Krunoslav Jakovina and Zvonimir Medverec for the cooperation in clinical work, and Neda Slade, Branko Brdar, Nancy Patten and Susan Ernster for assistance analyzing p53 mutational data and in determination of AA-DNA adducts. We are grateful to Arthur P. Grollman who encouraged our work.

The principal investigator, Professor Bojan Jelakovic, MD, PhD has full access to all of the data in the study and takes responsibility for the integrity of the data and the accuracy of the data analysis.

This research was supported by grants from the NIH Fogarty Center, NIEHS (ES-04068) and the Croatian Ministry of Science, Education and Sport \#108-0000000-0329.

\section{References}

1 Vanherweghem JL, Depierreux M, Tielemans C, Abramowicz D, Dratwa M, Jadoul M, Richard C, Vandervelde D, Verbeelen D, Vanhaelen-Fastre R: Rapidly progressive interstitial renal fibrosis in young women: association with slimming regimen including Chinese herbs. Lancet 1993;341:387-391.

-2 Vanhaelen M, Vanhaelen-Fastre R, But P, Vanherweghem JL: Identification of aristolochic acid in Chinese herbs. Lancet 1994;343:174.

-3 Cosyns JP, Jadoul M, Squifflet JP, De Plaen JF, Ferluga D, van Ypersele de Strihou C: Chinese herbs nephropathy: a clue to Balkan endemic nephropathy? Kidney Int 1994;45:1680-1688. 


\section{Kidney \\ Blood Pressure Research}

Kidney Blood Press Res 2013;37:1-8

DOI: 10.1159/000343394

Publisned ontrne: February 26, 2013

(C) 2013 S. Karger AG, Basel

www.karger.com/kbr

Karanović et al.: Chronic Dietary Intoxication as a Cause of Aristolochic Acid Nephropathy - a Case Report

4 Vanherweghem JL: Misuse of herbal remedies: the case of an outbreak of terminal renal failure in Belgium (Chinese herbs nephropathy). J Altern Complement Med 1998;4:9-13.

-5 Nortier JL, Martinez MC, Schmeiser HH, Arlt VM, Bieler CA, Petein M, Depierreux MF, De Pauw L, Abramowicz D, Vereerstraeten P, Vanherweghem JL: Urothelial carcinoma associated with the use of a Chinese herb (Aristolochia fangchi). N Engl J Med 2000;342:1686-1692.

6 Cosyns J-P, Jadoul M, Squifflet JP, Wese FX, van Ypersele de Stihou C: Urothelial lessons in Chinese-herb nephropathy. Am J Kidney Dis 1999;33:1011-1017.

7 Stiborová M, Frei E, Schmeiser HH: Biotransformation enzymes in development of renal injury and urothelial cancer caused by aristolochic acid. Kidney Int 2008;73:1209-1211.

8 Aristolochic acids, In: National Toxicology Program Report on Carcinogens 12th Ed. (2011) US Dept Health and Human Services, Public Health Service, Research, Triangle Park, North Carolina.

9 Hranjec T, Kovac A, Kos J, Mao W, Chen JJ, Grollman AP, Jelaković B: Endemic nephropathy: The case for chronic poisoning by Aristolochia. Croat Med J 2005;46:116-125.

10 Grollman AP, Shibutani S, Moriya M, Miller F, Wu L, Moll U, Suzuki N, Fernandes A, Rosenquist T, Medverec Z, Jakovina K, Brdar B, Slade N, Turesky RJ, Goodenough AK, Rieger R, Vukelić M, Jelaković B: Aristolochic acid and the etiology of (Balkan) endemic nephropathy. Proc Natl Acad Sci USA 2007;104:12129-12134.

11 Grollman AP, Jelaković B:. Role of Environmantal Toxins in Endemic (Balkan) Nephropathy. J Am Soc Nephrol 2007;18:2817-2823.

12 Jelaković B, Karanović S, Vuković-Lela I, Miller F, Edwards KL, Nikolić J, Tomić K, Slade N, Brdar B, Turesky RJ, Stipančić Ž, Dittrich D, Grollman AP, Dickman KG: Aristolactam-DNA adducts are a biomarker of environmental exposure to aristolochic acid. Kidney Int 2012;81:559-567.

13 Čeović S, Miletić-Medved M: Epidemiological features of endemic nephropathy in focal area of Brodska Posavina, Croatia. In: Čvorišćec, Čeović, Stavljenić-Rukavina, eds. Endemic nephropathy in Croatia. Zagreb: Academia Croatica scientiarum medicarum. 1996, p 7-21.

14 Petronić VJ, Bukurov NS, Djokić MR, Milenković DZ, Vuksanović AM, Avramović AD, Nale DP: Balkan endemic nephropathy and papillary transitional cell tumors of the renal pelvis and ureters. Kidney Int Suppl 1991;34:S77-S79.

15 Radovanović Z: Epidemiology and aethiology of endemic nephropathy. In: Radovanovic Z, Sindjic M, Polenkovic M, Djukanovic Lj, Petronic V, eds. Endemic nephropathy. Belgrade: Office for textbooks and teaching aids. 2000, p 22-135.

16 Grollman AP, Scarborough J, Jelaković B: Chapter 7 Aristolochic Acid Nephropathy: An Environmental and Iatrogenic Disease, In: James C. Fishbein, eds, Advances in Molecular Toxicology, New York,Elsevier, 2009, Vol 3, p 211-227.

17 Debelle FD, Vanherweghem JL, Nortier JL: Aristolochic acid nephropathy: a worldwide problem. Kidney Int 2008;74:158-169.

18 Fištrek M, Kovač-Peić A, Kos J, Pećin I, Barišić M, Hadžibegović I, Đanić A, Mišić M, Pavlović I, Dika Ž, MiletićMedved M, Cvitković A, Bistrović D, Grollman AP, Jelaković B: Ingestion of herbal tea in Croatian endemic area, International workshop on diagnostic criteria for endemic nephropathy, 5th Croatian congress on nephrology, dyalisis and transplantation with international participation, Brač, Croatia 2008.

19 Hranjec T, Kovač A,Kos J,Dika Ž, Brzić I, MaoW, Chen JJ, Grollman AP, Jelaković B: Dietary exposure to Aristolochia clematitis is a risk factor for endemic nephropathy. Coll Antropol 2006;30:S37.

20 Lord GM, Hollstein M, Arlt VM, Roufosse C, Pusey CD, Cook T, Schmeiser HH: DNA adducts and p53 mutations in a patient with aristolochic acid-associated nephropathy. Am J Kidney Dis 2004;43:e11-e17.

-21 Čvorišćec D, Čeović S, Boršo G, Stavljenić Rukavina A: Endemic Nephropathy in Croatia. Clin Chem Lab Med 1998;36:271-277.

-22 Bukvić D, Marić I, Arsenović A, Janković S, Djukanović L: Prevalence of Balkan endemic nephropathy has not changed since 1971 in the Kolubara region in Serbia. Kidney Blood Press Res 2007;30:117-123.

-23 Nortier JL, Schmeiser HH, Muniz Martinez MC, Arlt VM, Vervaet C, Garbar CH, Daelemans P, Vanherweghem JL: Invasive urothelial carcinoma after exposure to Chinese herbal medicine containing aristolochic acid may occur without severe renal failure. Nephrol Dial Transplant 2003;18:426-428.

24 Lo SH, Mo KL, Wong KS, Poon SP, Chan CK, Lai CK, Chan A: Aristolochic acid nephropathy complicating a patient with focal segmental glomerulosclerosis. Nephrol Dial Transplant 2004;19:1913-1915.

25 Mišić M, Vukelić M, Jakovina K, Medverec Z, Jakovina T, Stanić G, Jelaković B: Characteristics of urinary tract carcinomas in patients from endemic nephropathy and non-endemic areas in Slavonski Brod county in a 6-year period. Coll Antropol 2006;30:S67.

-26 Muniz Martinez MC, Nortier J, Vereerstraeten P, Vanherweghem JL: Progression rate of Chinese herb nephropathy: impact of of Aristolochia fangchi ingested dose. Nephrol Dial Transplant 2002;17:408-412. 